\title{
Cloud e-Learning: A New Challenge for Multi-Agent Systems
}

\author{
Krenare Pireva ${ }^{1}$, Petros Kefalas ${ }^{2}$, Dimitris Dranidis ${ }^{2}$, and \\ Thanos Hatziapostolou ${ }^{2}$ and Anthony Cowling ${ }^{3}$ \\ 1 South-East European Research Center, 24 P. Koromila, 54622, Thessaloniki, Greece \\ 2 The University of Sheffield International Faculty, City College, 3 L. Sofou, 54624, \\ Thessaloniki, Greece \\ 3 The University of Sheffield, Department of Computer Science, 211 Portobello \\ Street, Sheffield, UK
}

\begin{abstract}
The developments of pedagogical models in e-learning together with the advances of learning technologies and cloud computing give us confidence to believe that the traditional e-learning will evolve into a process which will put the learner in the center of educational provision. In this paper, we propose Cloud e-Learning, a new approach to e-learning that will be open and learner-centered, it will allow personalisation, it will enhance self-motivation and collaboration. The learners should be able to choose what to learn, what sources to use, with and by whom, how and in what pace, what services and tools to use, how to be assessed, whether to get credits towards a degree etc. In such a dynamic and complex environment, the need for Multi-Agents Systems is necessary. Actors in Cloud e-Learning would need automated facilitation in all services involved. We outline few indicative scenaria for Cloud E-Learning and we explain how smart agents can act on behalf of the learners, teachers and institution in order to maximise the benefit of the proposed concept.
\end{abstract}

\section{Introduction: from traditional e-Learning to Cloud e-learning}

Recent advances in Information and Communication Technologies have provided the opportunity to enhance e-learning with new synchronous and asynchronous features to both students and instructors. Educational institutions that provide e-learning can now develop courses and programmes that utilise existing pedagogies and experiment with new ones. It is apparent that these developments have lately facilitated the accessibility of e-learning through a wide variety of MOOCs (Massive Open On-line Courses).

A typical e-learning course, whether it is open or private, consists of four main components. The pedagogy should determine a number of characteristics for this course, such as the way in which the learning outcomes will be met by delivery and assessment methods as well as the learning path and learning pace 
of the group. Pedagogy will in broad terms define the balance between instruction and self-learning, implying also the type and frequency of communication (synchronous or asynchronous) between teachers and learners. The content will include a variety of text and media deemed as appropriate to give opportunities to meet the learning outcomes. The technological infrastructure is the set of Learning Technologies tools used by the teachers and learners in order to facilitate knowledge transfer and skill acquisition, such as VLE, teleconferencing tools, wikis, file sharing, social interaction, support and feedback etc. Finally, the course administration is a set of regulations and processes as well as their monitoring under which students enrol, attend, progress, etc.

Irrespectively of any combination of the above, e-learning inherits some rigidities of traditional face to face learning. The restrictions that, to a lesser or greater extent, characterise both types of learning are:

- teachers apply predefined pedagogies,

- the selection of material is largely done and/or recommended by the teacher,

- the tools of the technological infrastructure are specified by the course provider (teacher or institution),

- regulations and processes are provider/institution specific.

The big contradiction in this situation is that the learner, who is the receiver of the process, should abide by what the course providers have agreed, with no or little involvement in the above. This seems the "rational thing to do" for groups of learners, especially when providers are tied by the general educational framework in which they belong. Thus, for instance, Universities need to follow certain quality assurance requirements in order to award credits for courses and eventually degrees. But even then, course providers have been criticised that they do not apply a learner-centered approach, taking into account the individual types and needs of each learner.

In this respect, Cloud e-Learning can be considered as an advancement of e-Learning, taking into account that there exist courses in which learners can take the initiative to select:

- the way and pace in which they learn,

- the means through which knowledge and skills are acquired,

- the tools that they are going to use for learning,

- the people (teachers, facilitators, other learners with whom they wish to collaborate etc) and institutions involved in their leaning.

An immediate reaction to the above could be rather conservative, given our own experience in traditional education so far. Admittedly, however, reservations we all had one or two decades ago did not prevent the evolution of e-learning courses, for instance MOOCs, by respectable institutions which are available to masses of learners, even if this is currently done mostly without credits.

It is evident from the above that the proposed Cloud e-Learning is a complex venture that, despite all technical and pedagogical issues, allows for a certain amount of automation. It would be cumbersome if all the tasks are carried out 
manually on the responsibility of the learner. Facilitation is definitely required. Our position is that Cloud e-Learning is fertile ground for Multi-Agent Systems which would be responsible for such facilitation.

This is, in principle, a vision paper; our main contribution is to provide a definition of Cloud e-Learning and discuss how Multi-Agent Systems would play a strategic role in the development of this new concept. The paper is structured as follows: section 2 outlines Cloud e-Learning and its benefits to a learner-centered pedagogical approach. In section 3, we discuss Cloud Computing with regards to the proposed framework. Intelligent agents and their roles are presented in section 4 . Finally, we conclude by summarising the next potential research paths for Cloud e-Learning.

\section{A Vision for Cloud e-Learning}

There does not exist a widely accepted definition of Cloud e-Learning. It is meant to be a new term which we will not attempt to precisely define here but rather give its main characteristics. The aim of Cloud e-learning (CeL) is to provide personalised services that will increase interaction between users (learners, teachers and institutions) by sharing a pool of experiences and knowledge available in cloud and suggest structured courses that match learners preferences.

The important component in CeL is the Cloud and the opportunities it offers together with its existing infrastructure and services. The Cloud has opened up a range of possibilities for:

- enhanced distant collaboration,

- instant availability to web through a variety of devices,

- wide accessibility to information of different type,

- consolidating self-motivation,

- increase personalisation through combination of services,

- a variety of tools and services.

Let us consider some scenarios in CeL. The following may look at first glance as pedagogical and technological challenges but aim to unleash the full potential of $\mathrm{CeL}$ in the medium long term future (Table 1).

Table 1. Fundamental characteristics of CeL.

\begin{tabular}{ll}
\hline \multicolumn{1}{l}{ Cloud e-Learning Scenarios - Fundamental Question } \\
\hline \hline Open syllabus & What to learn? \\
\hline Open material & What sources to use? \\
\hline Open group & With and by whom? \\
\hline Open learning path & How and in what pace? \\
\hline Open assessment & How to be assessed? \\
\hline Open VLE & What services and tools to use? \\
\hline Open accreditation & How to get credits towards a degree?
\end{tabular}


Collective creation of syllabus: Imagine that a collaborative environment could be developed in which learners would be able to determine collectively the learning outcomes of a course. This could be done in accordance to some loose initial template that a teacher sketches. Learners will create a syllabus that emerges through individual preferences. Syllabi emergent learning outcomes will then drive teaching and assessment methods to reflect learners aims.

Collection of material through a variety of sources: Consider the variety of sources and their types (books, notes, libraries, video, audio, etc.) that exist in the web. Given semantic annotation to learning resources and processes, these could form a cloud of knowledge where learners could choose from. Suitability of sources would depend on learners learning style, past experience and popularity among learners and providers.

Selection of teachers, learners and providers: The learners would, in principle, be able to select by whom they are going to be tutored. In a cloud of teachers and providers globally accessible, a matching between learners and tutors would provide better opportunities for better learning experience. The same could apply for the selection of providers as well as fellow learners with common interests and similar personal development plans.

Learning path that match needs in pace: Learning paths may be personalised in terms of content, transition between steps, and pace for each step. This would assume existing experience of individual learners as well as other learners on similar course while taking into account individual learning styles, personal commitments, etc.

Personalisation of assessment according to learning type: Given the learning outcomes, there would be a variety of assessment methods that meet them. The learners, who would definitely be of different learning types and capacity, would be able to choose among the most suitable assessment for them, thus having more opportunities to achieve the aim of the course.

A customisable VLE: A user should be able to choose on a set of tools that facilitate their learning, rather than dealing with the fixed set of tools provided by a specific VLE. Thus, every learner would have a customised environment in which all processes will be accommodated in a way that would not require extra effort or deviation from everyday routine.

Configuration of course characteristics that may or may not lead to award of credits: Learners should be able to configure a course according to their need. Thus, it would be a different course which would satisfy personal interests, another which would be pursued for professional development and another which would lead to award of credits and eventually a degree. That would also need different levels of quality assurance and accreditation that would be specific from case to case.

Lastly, it is very important to note that the above seven characteristics of the CeL concept suggest that new ways for supporting learner engagement and motivation are required. Assuming, that learners choosing their learning is intrinsic motivation on its own, it is a wrong assumption to make. As a number of studies $[6,2]$ suggest, MOOCs currently face this challenge since dropout 
rates are very high despite the fact that people choose what courses to attend. In fact, all the privileges and flexibility in learning content, pace, methods of delivery and assessment offered by CeL actually bear an increased responsibility for supporting individual learner motivation. A dynamic learning setting that can change from face-to-face to online, within a programme of study or even within a course, that comprises of learners with different learning strengths, needs and backgrounds can be challenging and can easily lead to loss of learner motivation. Therefore, culturally responsive pedagogies that sustain the cognitive, behavioural and emotional engagement of learners must be a priority in CeL.

\section{Cloud Technologies and CeL}

\subsection{Cloud Computing}

Cloud computing enables access to a pool of resources (hardware and software) which are delivered over the Internet as services on demand. Renting services over the Internet is not something new $[16,24]$, since earlier ISPs provided software as services or applications as services. The main difference is that these earlier services faced long delays, low speed of network connection and lack of resources on demand. In addition, the renting resources needed to be scaled up manually. Cloud computing managed to overcome these problems by relying on a number of existing technologies such as virtualization, grid computing, and web services and by taking advantage of the following characteristics [18]: on-demand self-services, broad network access, resource pooling, rapid elasticity, measured services.

In a widely accepted model definition $[11,18,9,17,26]$, the cloud model is composed of the following service models:

- Software as a Service (SaaS). The cloud users have the capability to use applications which are installed in a cloud infrastructure and are being maintained by the service providers. The software services are accessible to users via thin-client interface devices (e.g. via a web-browser running on a desktop, laptop, handheld PDA, or smart-phone device) or to other applications via programmatic interfaces.

- Platform as a Service (PaaS). The providers provide the necessary programming languages, libraries, services, databases and tools so that cloud users can deploy their own applications onto the cloud in the form of SaaS.

- Infrastructure as a Service (IaaS). The cloud users have access to computing resources, such as processing, storage, and networks that are necessary in order to install operating systems and then deploy their applications.

The vendors are able to assign and split the resources on demand, such as processing and storing capacity. Besides other benefits, data storage space is not limited. This gives great opportunities for learners, teachers and educational institutions to literally access immeasurable amount of information. It is often 
the case, that educational institutions nowadays outsource part of their services to vendors such as Google. As the amount, diversity and quality of information grows, the ability of turning this information into useful knowledge by searching, reviewing, evaluating and synthesising becomes even more difficult, unless automated assistance is provided. This is the primary role of CeL.

\subsection{The CeL Layers}

As it has been stated above, the aim of CeL is to provide personalized services that will increase interaction between users (learners, teachers and institutions) by sharing a pool of experiences and knowledge available in cloud open courses and suggest structured courses that match learners preferences. Within the CeL platform all social networks as well as other vendors should be involved. CeL is proposed to have three layers where each layer has its own functionality (Fig. 1). The core layer of CeL will have a basic functionality and each outer layer will further increase the functionality of the framework:

- The Open Course Layer is proposed for learners who are interested to gain new knowledge or skills on a specific domain, without interest in acquiring accreditation, credits or degrees.

- In principle, CeL should be designed to offer courses with credits, which implies that within these courses the students will be assessed and get credits. Accreditation is required to be sought for Universities which provide such courses. The Credit Bearing Course Layer extends the functionality of core layer applies for those learners who are interested in getting credits on the CeL courses that they will attend.

- Finally, CeL should act as a virtual university which will inherit all characteristics of university establishments, such as accreditation, credits, quality assurance and monitoring, regulations etc. The Degree Award Programme Layer extends the functionality of second layer further and it offers services for those learners who are interested to acquire degrees from CeL.

The three different layers have different inherent complexities. At the core level, CeL would not so much require collaboration between teachers and institutions. At outer level, where degrees could be awarded would need rather complex arrangements which will mostly deal with accreditation and quality assurance. Thus, for instance, at Open Course layer, learners would need to collaborate for open syllabus as well as emergent collection of appropriate material, which after personalisation, each leaner would follow an individual learning path with no further commitments with regard to assessment. In Credit Bearing level, the teachers of an establishment would need to collaborate in order to establish some requirements, including assessment, under which award of credits from that establishment would be possible. That would need compliance with local quality assurance standards. Finally, at Degree Award level, various institutions need to collaborate in order to provide courses that meet national and international prerequisites for quality assurance and accreditation. Actually, the outer level of 


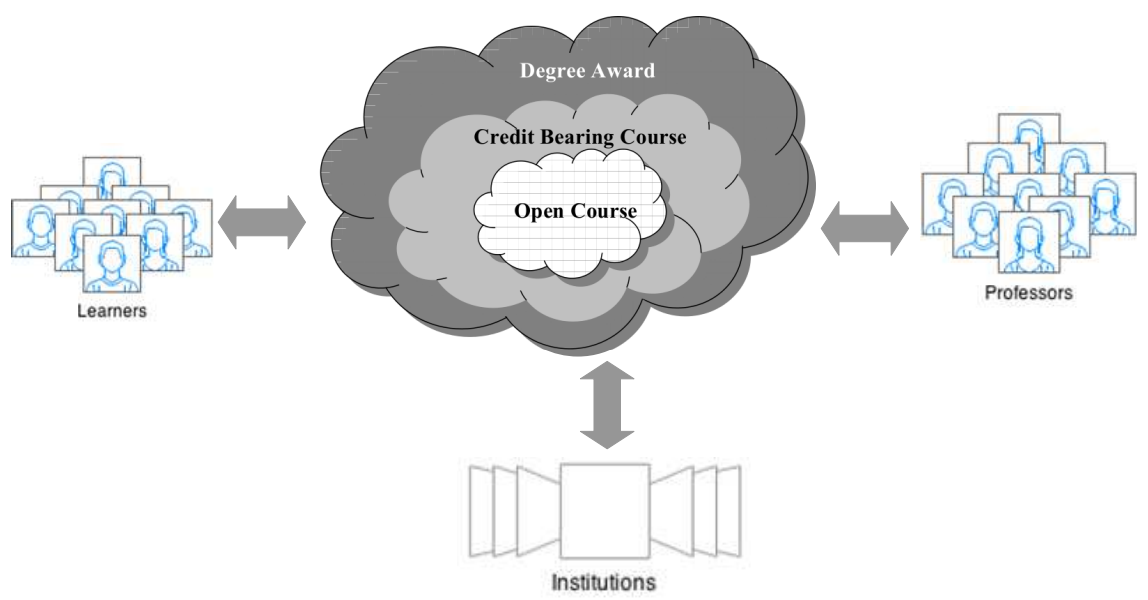

Fig. 1. Layers of Cloud e-learning and its main Actors.

CeL would form the virtual meta-University in which the learners should be able to choose among various University providers and available credit bearing courses. In brief, Table 2 summarises the requirements at each layer.

Table 2. Requirements for CeL layers and complexities implied.

\begin{tabular}{llll}
\hline Requirements & $\begin{array}{l}\text { Open } \\
\text { Course }\end{array}$ & $\begin{array}{l}\text { Credit } \\
\text { Bearing }\end{array}$ & $\begin{array}{l}\text { Degree } \\
\text { Award }\end{array}$ \\
\hline \hline Collaboration between Learners & desirable & desirable & desirable \\
\hline Collaboration between Teachers & optional & desirable & necessary \\
\hline Collaboration between Institutions & - & optional & desirable \\
\hline Quality Assurance at local level & optional & desirable & necessary \\
\hline Quality Assurance at National level & - & desirable & necessary \\
\hline Quality Assurance at International level - & optional & necessary \\
\hline Accreditation & - & optional & desirable \\
\hline
\end{tabular}

\subsection{The CeL Actors}

As mentioned already, the CeL main actors would be: (a) Learners, (b) Teachers, and (c) Institutions. Table 3 summarise a comparison between traditional elearning and $\mathrm{CeL}$ for each of these types of actors.

\section{The Challenge for Multi-Agent Systems}

The key issues of CeL are: (a) learner-centered, (b) openness, (c) personalisation, (d) self-motivation and (e) collaboration. In the previous sections, we have 
Table 3. The comparison between traditional e-learning and cloud e-learning from each actor's prospective.

\begin{tabular}{|c|c|c|}
\hline & Traditional e-Learning & Cloud e-Learning \\
\hline 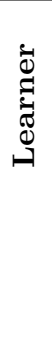 & $\begin{array}{l}\text { Learners access access their univer- } \\
\text { sity courses. They collaborate inter- } \\
\text { nally within their institution. They } \\
\text { have access to the material devel- } \\
\text { oped by their local teacher. The dis- } \\
\text { cussion around the subject of study } \\
\text { is mostly constraint within the Uni- } \\
\text { versity. }\end{array}$ & $\begin{array}{l}\text { Learners are offered open materials } \\
\text { that are developed by various insti- } \\
\text { tutions. They have access to other } \\
\text { learners and teachers from other in- } \\
\text { stitutions. They use a variety of } \\
\text { tools. They are flexible to decide } \\
\text { what they want to learn, when to } \\
\text { learn, from whom to learn and how } \\
\text { to learn. }\end{array}$ \\
\hline 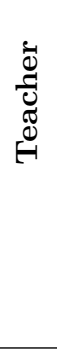 & $\begin{array}{l}\text { Teachers are restricted to choose } \\
\text { among traditional teaching, learn- } \\
\text { ing and assessment methodologies } \\
\text { for learners, in a kind of one-size- } \\
\text { fits-all way. They deal only with } \\
\text { students within their institutional } \\
\text { class. They are restricted to use the } \\
\text { institutional VLE for all activities. }\end{array}$ & $\begin{array}{l}\text { Teachers are open to collabora- } \\
\text { tion and scrutiny from colleagues } \\
\text { at other institutions. Competition } \\
\text { will act as a driver to achieve bet- } \\
\text { ter quality and disseminate best } \\
\text { practices and inspiration to others. } \\
\text { They will use a customisable VLE } \\
\text { but some of them will be suscepti- } \\
\text { ble to resistance to change. }\end{array}$ \\
\hline 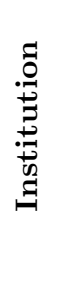 & $\begin{array}{l}\text { Institutions apply their internal } \\
\text { monitoring of quality assurance. } \\
\text { They define their own programmes } \\
\text { and curricula. Learners and teach- } \\
\text { ers abide by the institutional regu- } \\
\text { lations and procedures. }\end{array}$ & $\begin{array}{l}\text { Institutions will be forced to pro- } \\
\text { vide better service to learners and } \\
\text { better policies for teachers. They } \\
\text { will have to negotiate quality assur- } \\
\text { ance and accreditation and as a re- } \\
\text { sult upgrade the standards of edu- } \\
\text { cation provision in global compet- } \\
\text { ing market. }\end{array}$ \\
\hline
\end{tabular}

outlined the environment (CeL) and the actors involved (learners, teachers and institutions). It is believed that CeL will be such a dynamic and complex environment that the actors could not manage it without help. This is where MultiAgents Systems (MAS) involvement is needed. In this context, the intelligent (for others just "smart") counterparts of agents are considered. These agents should be able to facilitate the process of learning by acting on behalf of the actors in certain complex tasks. Intelligent agents are distinguished from ordinary programs by the degree of autonomy, goal-orientation and ability to reason, reactiveness and interaction, collaboration, negotiation through communication with other agents or humans. Secondary attributes, such as learning, rationality, mobility could also play an important role in the CeL context.

The Semantic Web is thought to be an incubator where smart agents can grow and unleash their potential. Smart agents can be thought as a semantic web service. However, a semantic web service is an abstract functionality which may be implemented by one or more smart agents (w3c). In CeL, semantic 
annotation and ontologies are by default necessary and therefore the deployment of semantic cloud services through intelligent agents would be the essence of its desired functionality [25].

CeL offers students, teachers and institutions the highest level of learning and teaching flexibility and promotes exploration of new pedagogies. Successful implementation of MAS in such a learning environment mandates the interoperability of e-learning content and systems through standardisation. The need for interoperable e-learning systems has long been recognised and several learning resource specifications have emerged in the last fifteen years. Popular standards include the Learning Resource Metadata Specification and Content Packaging by the IMS Global Consortium [14] and the Learning Object Metadata (LOM) by IEEE [13]. The e-learning standard, however, that has gained the most widespread adoption and is supported by most major vendors of Learning Management Systems [21] is the Sharable Content Object Reference Model (SCORM) by ADL [1]. SCORM actually integrates the e-learning specifications created by IMS and IEEE into a consolidated model that enables the construction of reusable, accessible, durable and interoperable web-based learning content which is assigned descriptive metadata in order to form learning objects. Depending on the nature of a learning object such metadata can be technical (e.g. size, format) or educational (e.g. learning outcome, context, level of difficulty). The CeL characteristics presented in Table 1, however, necessitate the development of new or the extension of existing standards and metadata in order to enable intelligent MAS to support the flexibility that this learning and teaching paradigm offers.

The use of MAS in e-learning is not a new concept. Agents were proposed in many phases of learning, such as formative assessment [20], personal tutors [12, 3], skill management [10], learning paths [7], personalised content search [19], communities for group collaboration [27, 23], affective facilitation [5], and many more. Various applications in e-learning [15] and frameworks with MAS were also proposed $[22,8,4]$. With the development of e-learning to CeL, all the above and more automated on line assistants will be needed. As CeL will:

- provide personalised services,

- increase interaction between users,

- allow sharing of pool of experiences and knowledge resources,

- recommend learning structures to users, and

- do matchmaking of resources and users,

the agents employed would have certain characteristics. Profile Development Agents will be responsible to build a profile for individual learners, teachers and institutions. Profiles will be based on preset configuration but also learning (gathering and mining data) from individuals behaviours in a period of time. Matching Agents will attempt to match profiles of individuals to learning content. teachers and institutions, taking also into account preferences that other individuals have expressed over a period of time and past experience on successful match making. A type of matching agent, Collaboration Agents will 
create communities of learners and teachers who are most likely to have better collaboration. Searching Agents will have the task to perform intelligent search through a cloud of knowledge in order to find the best fit with regards to learning content and actors. A variety of Course Agents will use results to compose learning collections, ranging from personal syllabi to learning objects and personalised learning paths. Similarly, Programme Agents will perform equivalent tasks for teachers and institutions, taking into account regulatory frameworks for award of credits and degrees. Learners will be assisted in their learning process by Performance Monitoring Agents who will be able to recommend alternatives if the progress is different from the desired. Configuration Agents will suggest the best tools available to individuals in order to surpass technological difficulties not related directly to the learning process. Finally, Affective Emotional Agents, probably presented as anthropomorphic on-line companions, will take into account the emotional state of the learners and adjust the learning process accordingly. Needless to say that interaction between all agent types will be essential to achieve the emergent CeL result.

\section{Conclusions}

We have defined Cloud e-Learning characteristics and justified why CeL goes hand in hand with advances in Multi-Agent Systems. This new framework for learning can be used as a gateway to open available courses from different institutions. The proposed layers allow students to learn anything, with or without credits, with or without a degree. Learners will have the ability to gain top quality on-line education through choosing the best teachers. Teachers will collectively develop top quality content, and institutions will compete for offering top quality programmes. The big picture of CeL is hard to deploy to full extend. Every individual aspect of CeL is by itself a research area that can be further developed. The vision for CeL, as described in this paper, provides a number of pedagogical and technological challenges which need to be addressed in the coming decades.

\section{References}

1. ADL Technical Team: SCORM 2004 4th Edition Specification, http://www.adlnet.gov/scorm/scorm-2004-4th/

2. Belanger, Y., Thornton, J.: Bioelectricity: A quantitative approach duke universitys first mooc (2013)

3. Bennane, A.: Tutoring and multi-agent systems: Modeling from experiences. Informatics in Education-An International Journal (Vol 9_2), 171-184 (2010)

4. Bhavsar, V., Boley, H., Yang, L.: A weighted-tree similarity algorithm for multiagent systems in e-business environments (2004)

5. Chatzara, K., Karagiannidis, C., Stamatis, D.: Students attitude and learning effectiveness of emotional agents. In: Advanced Learning Technologies (ICALT), 2010 IEEE 10th International Conference on. pp. 558-559. IEEE (2010) 
6. Daniel, J.: Making sense of moocs: Musings in a maze of myth, paradox and possibility. Journal of Interactive Media in Education 3 (2012)

7. Draganidis, F., Chamopoulou, P., Mentzas, G.: An ontology based tool for competency management and learning paths. In: 6th International Conference on Knowledge Management (I-KNOW 06). pp. 1-10 (2006)

8. Fenton-Kerr, T., Clark, S., Cheney, G., Koppi, T., Chaloupka, M.: Multi-agent design in flexible learning environments. In: ASCILITE. vol. 98, p. 223 (1998)

9. Galen, G., Eric, K.: What cloud computing really means (April 2008), http://www.infoworld.com/d/cloud-computing/what-cloud-computing-reallymeans-031

10. Garro, A., Palopoli, L.: An xml multi-agent system for e-learning and skill management. In: Agent Technologies, Infrastructures, Tools, and Applications for EServices, pp. 283-294. Springer (2003)

11. Geelan, J.: Twenty one experts define cloud computing (August 2008), http://virtualization.sys-con.com/?q=node/612375

12. Gladun, A., Rogushina, J.: An ontology-based approach to student skills in multiagent e-learning systems (2007)

13. IEEE Learning Technology Standards Committee: IEEE 1484.12.1-2002 Learning Object Metadata standard, http://ltsc.ieee.org/wg12/index.html

14. IMS Global Learning Consortium Inc.: IMS Learning Resource Meta-data Specification V1.3, http://www.imsproject.org/metadata/index.html

15. Ivanovic, M., Jain, L.C. (eds.): E-Learning Paradigms and Applications - Agentbased Approach, Studies in Computational Intelligence, vol. 528. Springer (2014)

16. Kaur, M., Kaur, A., et al.: A review article of cloud computing. International Journal of Computers \& Technology 4(1), 102-105 (2013)

17. McFedries, P.: The cloud is the computer (April 2008), http://spectrum.ieee.org/computing/hardware/the-cloud-is-the-computer

18. Mell, P., Grance, T.: The nist definition of cloud computing (draft). NIST special publication 800(145), 7 (2011)

19. Orzechowski, T.: The use of multi-agents' systems in e-learning platforms. In: Control and Communications, 2007. SIBCON'07. Siberian Conference on. pp. 64-71. IEEE (2007)

20. Otsuka, J.L., Bernardes, V.S., Rocha, H.: A multiagent system for formative assessment support in learning management systems. In: Anais do I Workshop Tidia, São Paulo (2004)

21. Shih, W.C., Yang, C.T., Tseng, S.S.: Ontology-based content organization and retrieval for scorm-compliant teaching materials in data grids. Future Generation Computer Systems 25(6), 687-694 (2009)

22. Stamatis, D., Kefalas, P., Kargidis, T.: A multi-agent framework to assist networked learning. Journal of computer assisted learning 15(3), 201-210 (1999)

23. Stamatis, D., Kefalas, P., Tsadiras, A.: Networked academic societies in collaborative development of e-learning courses. In: Fifth International Conference of Networked Learning, Lancaster, UK (2006)

24. Sultan, N.: Cloud computing for education: A new dawn? International Journal of Information Management 30(2), 109-116 (2010)

25. Talia, D.: Cloud computing and software agents: Towards cloud intelligent services. In: WOA. pp. 2-6 (2011)

26. Vaquero, L.M., Rodero-Merino, L., Caceres, J., Lindner, M.: A break in the clouds: towards a cloud definition. ACM SIGCOMM Computer Communication Review $39(1), 50-55(2008)$ 
27. Yang, F., Han, P., Shen, R., Kraemer, B.J., Fan, X.: Cooperative learning in selforganizing e-learner communities based on a multi-agents mechanism. In: AI 2003: Advances in Artificial Intelligence, pp. 490-500. Springer (2003) 